\title{
INVESTIGATION OF OXIDE BIFILMS IN INVESTMENT CAST SUPERALLOY IN100
}

\author{
M.A. Kaplan, R.K. Guarriello, G.E. Fuchs \\ Department of Materials Science and Engineering \\ University of Florida, Gainesville, FL 32611-6400, USA
}

Keywords: IN100, Investment Casting, Superalloys, bifilms, inclusions

\begin{abstract}
Oxide bifilms are a recently proposed casting inclusion reported to have been observed in vacuum investment cast polycrystalline Ni-base superalloys. The effect of casting atmosphere, turbulence, filtering, hot isostatic pressing (HIP), and heat treatment have been investigated to identify the critical parameters that have been reported to result in bifilm formation in Ni-based superalloys. Room temperature tensile and room temperature fatigue testing was used to identify the effects of each casting and processing parameter on casting anomaly formation and the resultant effects on mechanical properties. Analyzed tensile and fatigue data did not indicate an influence of bifilms on the tensile or fatigue strength of vacuum processed IN100. Bifilms were not observed, via the characterization methods utilized, to be an active mechanism in tensile or fatigue fracture.
\end{abstract}

\section{Introduction}

A recently proposed casting inclusion, oxide bifilms, has been reportedly observed in polycrystalline investment cast $\mathrm{Ni}$ based superalloy systems $[1,2]$. The presence of oxide bifilms in Ni-superalloy systems are of particular interest because at least two turbine blade failure events have been attributed to bifilms in cast superalloy components [1].

Bifilm formation is theoretically possible whenever a molten metal capable of forming a solid and continuous oxide is exposed to turbulence. The molten metal is reported to react with its casting atmosphere and forms an approximately 1-20 nm thick oxide skin, which, due to surface perturbations of the fluid, can cause the oxide to fold and become entrained into the melt [3-7]. This is shown schematically in Figure 1. It's also been reported that the formation of this oxide skin is possible with vacuum cast components, and that residual oxygen in the casting chamber is sufficient for bifilm formation [1-3, 5, 8].

Bifilms have been reported to have a strongly negative impact on tensile and fatigue properties. However, the presence of bifilms has not been clearly demonstrated in the current limited literature. Often times, the presence of bifilms is often reported by identifying debits to mechanical properties, and correlating such reductions to casting conditions that would be favorable for bifilm formation [3, 5, 9-16]. However, the material systems in which such analysis has been done is limited, and much of the current research pertains to air-cast, aluminum-based systems. Since bifilms have been reportedly observed in polycrystalline investment cast Ni-based superalloy systems, the current study attempts to produce and image a bifilm and to determine if such debits or improvements to mechanical test data can be observed in the widely used Ni-base superalloy IN100.

\section{Experimental Procedures}

The alloy selected for investigation was polycrystalline investment cast IN100 (Table I). The sulfur content of the alloy was reported to be $<0.001 \mathrm{wt} \%$. This alloy was selected for this study because it was the material utilized in the component identified by Campbell and Tiryankioglu [1] as the cause of the fatal aircraft crash. A wide variety of processing and casting parameters were investigated to determine the effect of each on material properties and inclusion/anomaly formation (Table II). All material analyzed was supplied by Alcoa Howmet, and all casting was performed by Alcoa Howmet Research Center in Whitehall, MI. Vacuum casting was conducted using standard VIM and investment casting procedures.

(a)

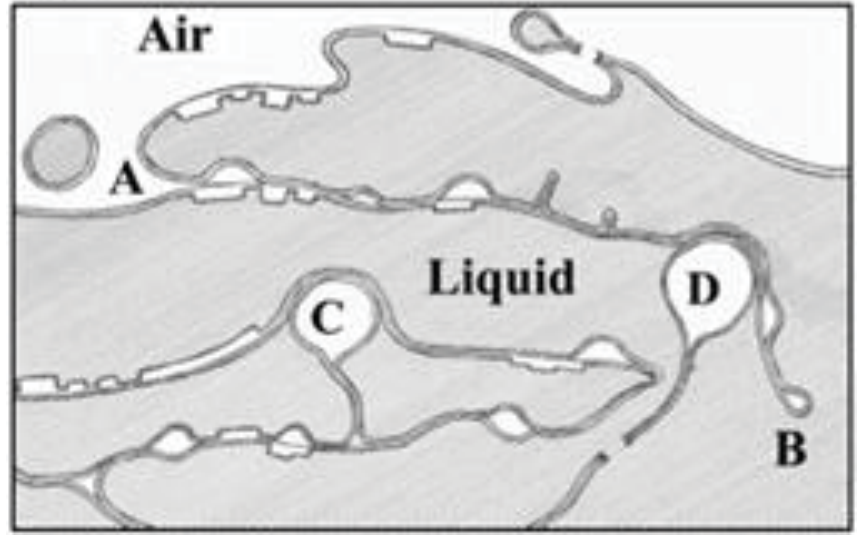

(b)

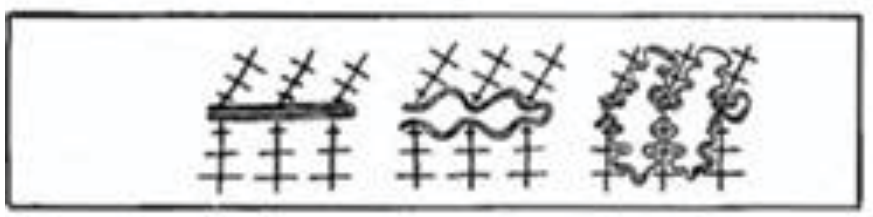

Figure 1 - Schematic representation of bifilm behavior. (a) Bifilm formation creating pre-existing crack from $\mathrm{A}$ to $\mathrm{B}$, and creation of bubbles $\mathrm{C}$ and $\mathrm{D}$ [3]. (b) Bifilm assisted casting porosity formation [3].

Table I - Nominal Composition of IN100 Test Samples (wt $\%$ )

\begin{tabular}{|c|c|c|c|c|c|c|c|c|c|}
\hline $\mathrm{Ni}$ & $\mathrm{Cr}$ & $\mathrm{Co}$ & $\mathrm{Mo}$ & $\mathrm{Ti}$ & $\mathrm{Al}$ & $\mathrm{V}$ & $\mathrm{C}$ & $\mathrm{B}$ & $\mathrm{Zr}$ \\
\hline $\mathrm{Bal}$ & 8.57 & 14.05 & 2.93 & 4.62 & 5.64 & 0.79 & 0.16 & 0.02 & 0.04 \\
\hline
\end{tabular}

For each casting environment, samples were either top or bottom filled and in some cases turbulators were included, to evaluate the effect of turbulence during pouring. Some samples from each casting condition were hot isostatically pressed (HIP) and heat treated. HIP'ing was performed to reduce the presence of porosity and evaluate the proposed mechanisms for healing of bifilms. 
Table II - Test Matrix of Material Conditions

\begin{tabular}{|c|c|c|c|c|c|}
\hline Environment & Filtering & Fill Condition & Gating & Processing & Heat Treatment \\
\hline \multirow{8}{*}{ Vacuum } & \multirow{8}{*}{ No Filter } & \multirow{4}{*}{ Top Fill } & \multirow{2}{*}{ Conventional } & HIP & Heat Treat \\
\hline & & & & No HIP & Heat Treat \\
\hline & & & \multirow{2}{*}{ Turbulent } & HIP & Heat Treat \\
\hline & & & & No HIP & Heat Treat \\
\hline & & \multirow{4}{*}{ Bottom Fill } & \multirow{2}{*}{ Conventional } & HIP & Heat Treat \\
\hline & & & & No HIP & Heat Treat \\
\hline & & & \multirow{2}{*}{ Turbulent } & HIP & Heat Treat \\
\hline & & & & No HIP & Heat Treat \\
\hline \multirow{4}{*}{10 Torr Argon } & \multirow{4}{*}{ No Filter - } & \multirow{2}{*}{ Top Fill } & \multirow{2}{*}{ Conventional } & HIP & Heat Treat \\
\hline & & & & No HIP & Heat Treat \\
\hline & & \multirow{2}{*}{ Bottom Fill } & \multirow{2}{*}{ Conventional } & HIP & Heat Treat \\
\hline & & & & No HIP & Heat Treat \\
\hline \multirow{6}{*}{ Air } & \multirow{3}{*}{ No Filter } & \multirow[b]{2}{*}{ Top Fill } & \multirow[b]{2}{*}{ Conventional } & HIP & Heat Treat \\
\hline & & & & No HIP & $\begin{array}{c}\text { Heat Treat } \\
\text { As Cast }\end{array}$ \\
\hline & & Bottom Fill & Conventional & HIP & Heat Treat \\
\hline & \multirow{3}{*}{ Filter } & \multirow{3}{*}{ Top Fill } & \multirow{3}{*}{ Conventional } & HIP & Heat Treat \\
\hline & & & & No HIP & Heat Treat \\
\hline & & & & & As Cast \\
\hline
\end{tabular}

Room temperature tensile properties were determined in order to minimize fracture surface oxidation, which could potentially be indistinguishable from a preexisting oxide bifilm. Cylindrical samples were tested at a constant cross-head speed throughout the test to produce an initial strain rate of $0.1 / \mathrm{min}$. Fracture surfaces were removed and mounted for fractographic analysis. A portion of the gauge section was cross-sectioned and metallographic characterized in the area near the fracture surface. Fractographic and metallographic characterization was conducted using scanning electron microscopy (SEM) and energy dispersive $\mathrm{x}$-ray spectroscopy (EDS).

Room temperature high cycle fatigue (HCF) properties were also determined using cylindrical samples tested in a servohydraulic system at a frequency of $20 \mathrm{~Hz}$. Again, room temperature was selected to minimize fracture surface oxidation, since this could be misidentified as an oxide bifilm. This condition was also expected to be sensitive to the presence of inclusions [17-19]. Fracture surfaces were removed and mounted for fractographic analysis via SEM.

Metallographic specimens were prepared by standard metallographic procedures and, in some cases, by deep etching. Metallographic samples were analyzed by SEM. To further characterize their structure, some inclusions observed via SEM were removed using focused ion beam (FIB) lift-out for TEM analysis. A detailed analysis of the fracture surface was also performed in each condition, using Auger microscopy under ultrahigh vacuum conditions. The fracture surfaces were immediately analyzed to prevent contamination from adsorption formation of an oxide monolayer. Elemental depth profiling was also performed.

To further characterize the structure of oxycarbide inclusions, some oxycarbide inclusions observed metallographically by SEM were removed via focused ion beam (FIB) lift-out for TEM analysis. Metallographically prepared samples had to be carefully removed from epoxy mounts via mechanical fracture, then cleaned and mounted on an aluminum SEM stub. FIB was performed with an FEI Strata DB 235 dual beam FIB/SEM equipped with a liquid metallorganic ion source (LIMS) for protective Pt layer deposition. Samples were prepared using standard FIB lift-out procedures. The samples were then thinned, mounted, and removed for TEM analysis.

At least one blade from each blade sample condition (Table III) was used to machine Auger pins. Pins from each condition were used for in-situ fractographic Auger analysis. The Auger pins were cylindrical notched samples $20.3 \mathrm{~mm}$ in length and $3.18 \mathrm{~mm}$ in diameter. A blunt notch was machined $11.4 \mathrm{~mm}$ from the top of the sample, and to a depth of $0.51 \mathrm{~mm}$. Each Auger pin was loaded into a PHI 660 scanning Auger multiprobe and fractured in-situ with an actuating hammer. In-situ fracture occurred in ultra-high vacuum conditions of less than 0.5 nTorr nominal chamber pressure. Fracture surfaces of samples were immediately analyzed to prevent contamination due to adsorption formation of an oxide monolayer. The selection of the maximum nominal pressure was based on the results of prior kinetic studies of nickel oxidation in which it was determined that a monolayer of $\mathrm{NiO}$ forms in about 1 second at nominal pressures of $10^{-6}$ Torr [16]. Elemental depth profiling was performed using a rastering $\mathrm{Ar}$ ion beam to mill the sample surface. The ion beam raster area was adjusted to set milling rates of material removal, and was adjusted to meet the desired material removal rate. Sputter time was recorded while depth profiling, and compared to milling rates of a $\mathrm{Ta}_{2} \mathrm{O}_{5}$ standard of known thickness using identical ion beam conditions. This allowed for estimations of sputter depth with time, and estimations of elemental content as a function of depth.

\section{Results and Discussion}

Although bifilm theories suggest that the introduction of turbulence during casting results in the formation of bifilms $[1,3$, $5,8,20]$, there was no discernible difference in the room temperature UTS in vacuum and argon cast samples (Figure 2).

(a)

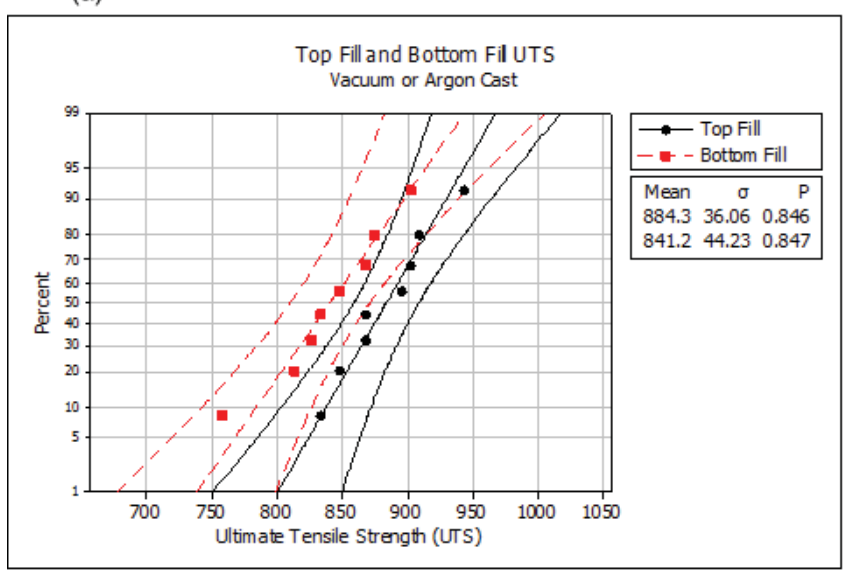

(b)

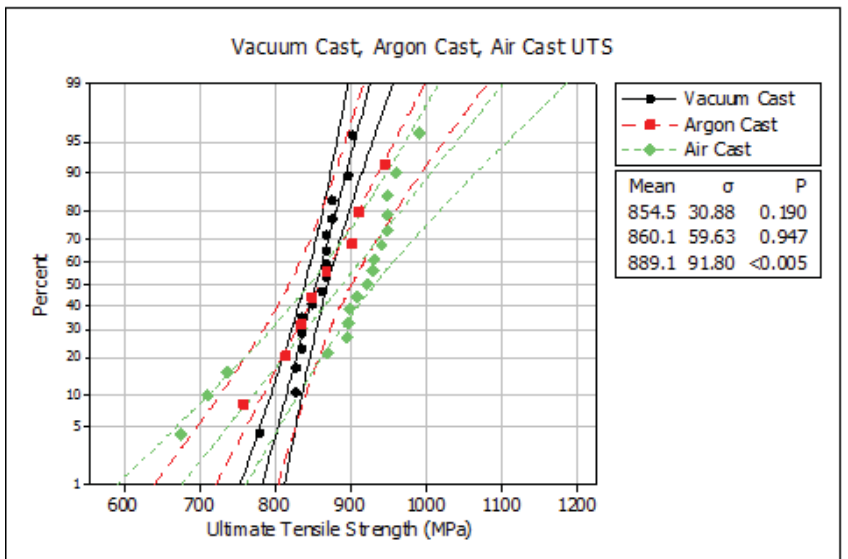

Figure 2 - Comparison of UTS properties. (a) Probability plot of UTS for top filled vacuum cast and argon cast samples and bottom fill vacuum cast and argon cast samples. (b) Probability plot of UTS for vacuum cast, argon cast, and air cast samples. 
There was also no discernible variation in elongation between top filled or bottom filled samples (Figure 2). There did appear to be an influence of casting atmosphere on UTS. There was also an influence of casting atmosphere on ductility (Figure 3). This is apparent from the dramatic reduction in minimum elongation seen in air cast samples. There did not appear to be an effect (Figure 4) of processing variables on yield stress (YS).

(a)

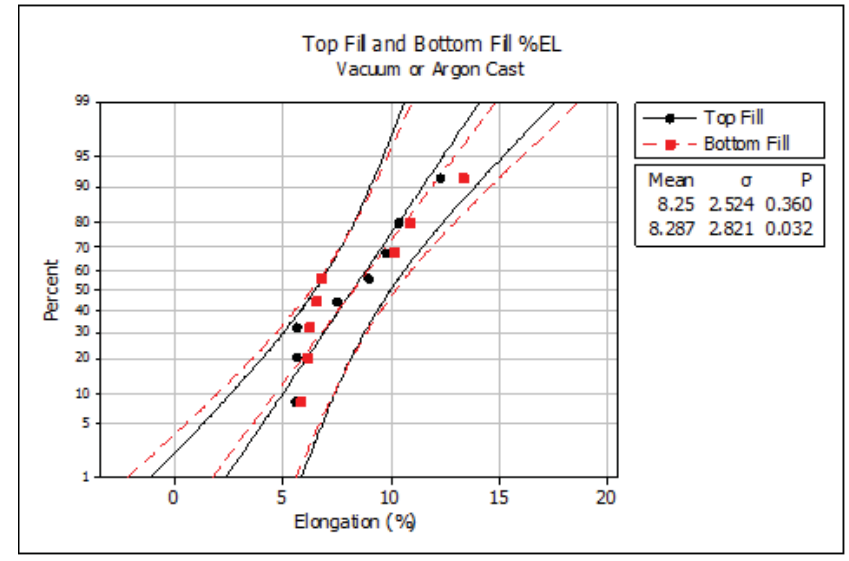

(b)

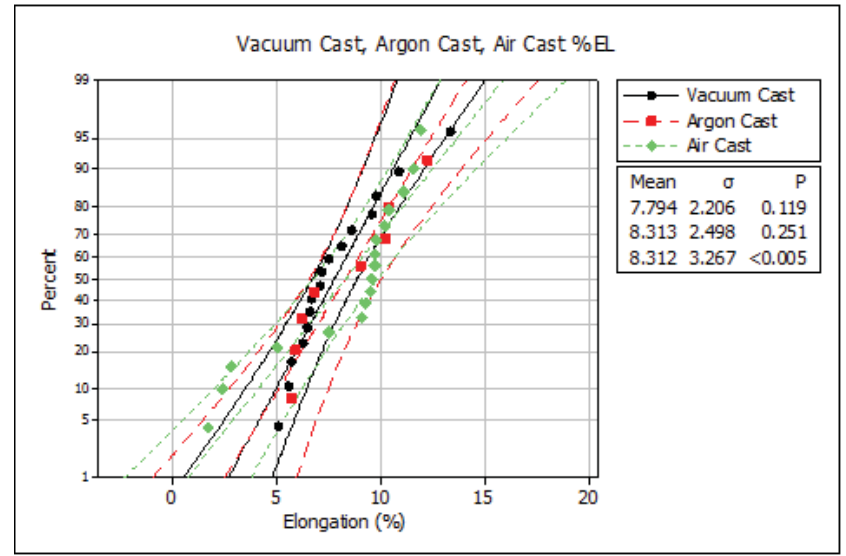

Figure 3 - Elongation results from varying process parameters. (a) Probability plot of elongation for top fill vacuum cast and argon cast samples and bottom fill vacuum cast and argon cast samples. (b) Probability plot of elongation for vacuum cast, argon cast, and air cast samples.

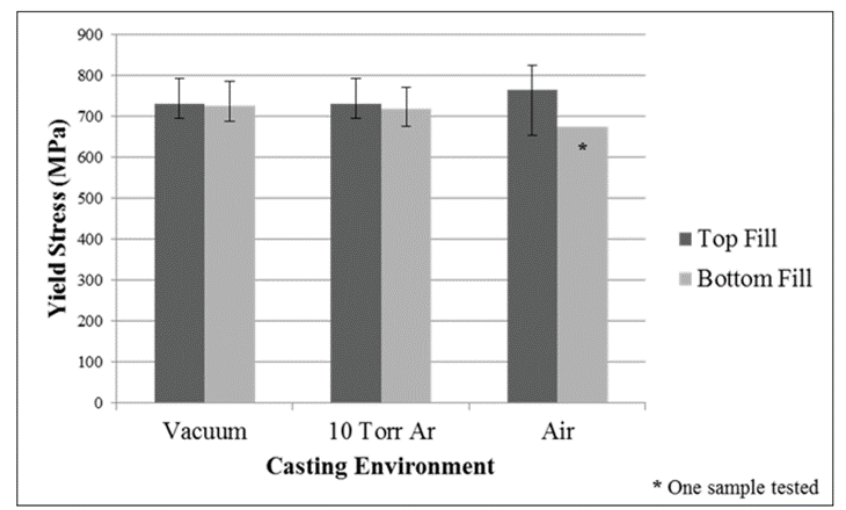

Figure 4 - Maximum, minimum and mean yield strength (YS) values for all fill conditions and casting atmospheres
No vacuum or argon cast tensile samples exhibited any evidence of fracture due to inclusions. The tensile fracture of air cast samples was typically dominated by the presence of inclusions. Turbulators added to the gating of castings and HIP'ing did not exhibit a significant effect on UTS or elongation of either vacuum or argon cast samples.

There was no discernible improvement in fatigue life from bottom filling investment castings. If there were bifilms in top filled samples, it is expected that top filled samples would exhibit a significantly reduced HCF lifetime. Casting atmosphere did have a significant effect on fatigue life. Air cast samples exhibited a significantly reduced average fatigue life (Figure 5).

Additionally, there was no significant degradation of fatigue properties from increasing casting turbulence via the utilization of turbulators in the gating of vacuum and argon cast material (Figure 5). Comparison of the most turbulently cast samples (with turbulators) to the least turbulently cast samples (bottom cast without turbulators) did not show a statistically significant difference in HCF lifetime.

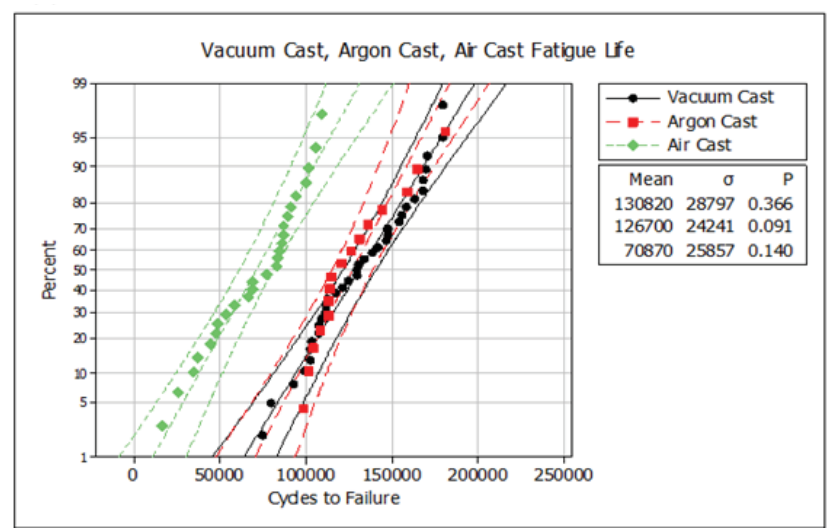

Figure $5-\mathrm{HCF}$ results from varying process parameters. Probability plot of fatigue life for all vacuum, argon and air cast samples.

\section{Auger Characterization:}

Auger samples from each condition were characterized in an effort to determine if these fractographic features had formed due to bifilm splitting (Figure 6). In all of the Auger pins fractured, none exhibited AES spectra indicative of an oxide film. In fact, all generated data that is indistinguishable from matrix material. This indicates that many fractographic features are not due to bifilm splitting. Such fracture surface features are more than likely formed due to the classic theory of crack propagation, and are unrelated to the presence of an oxide film.

Significant microvoid formation was observed in fractured Auger pins due to fractured MC-type carbides. In all of the pins fractured and all of the microvoids analyzed, fractured carbides characterized in all specimen conditions yielded substantial $\mathrm{C}, \mathrm{Ti}$, and Mo peaks, but did not indicate the presence of an oxide or yield observable $\mathrm{O}$ or $\mathrm{Al}$ peaks.

In some air cast samples, Ti oxycarbide inclusions could be observed on the fracture surface of some Auger pins. Discontinuous oxide structures were identified overlaying very large $\mathrm{M}(\mathrm{Ti}, \mathrm{Mo}) \mathrm{C}$ carbides. These types of large inclusions were the only instance in which any form of oxide structure could be identified in a fractured Auger pin. However, the oxides were patchy and discontinuous as opposed to a continuous film, 
(a)

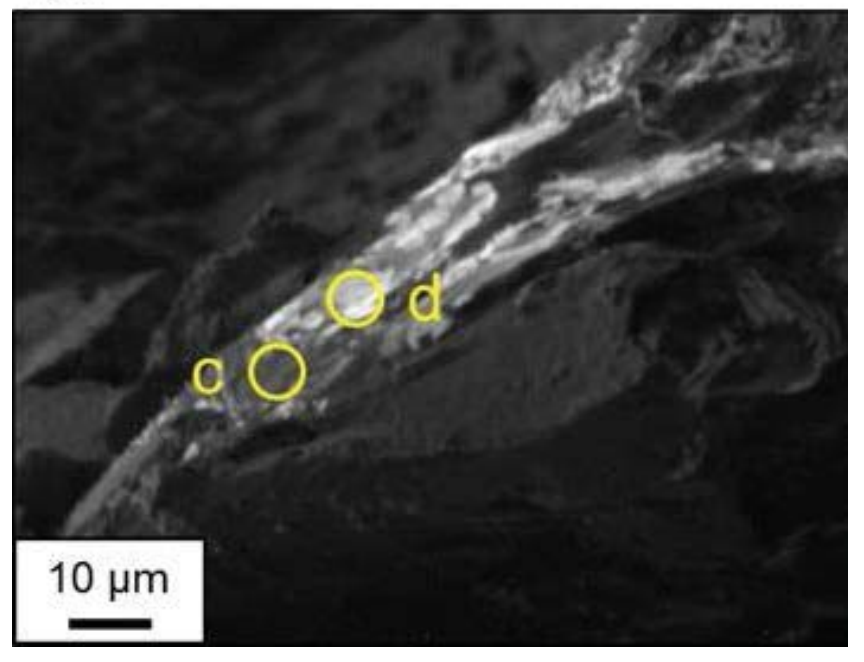

(b)

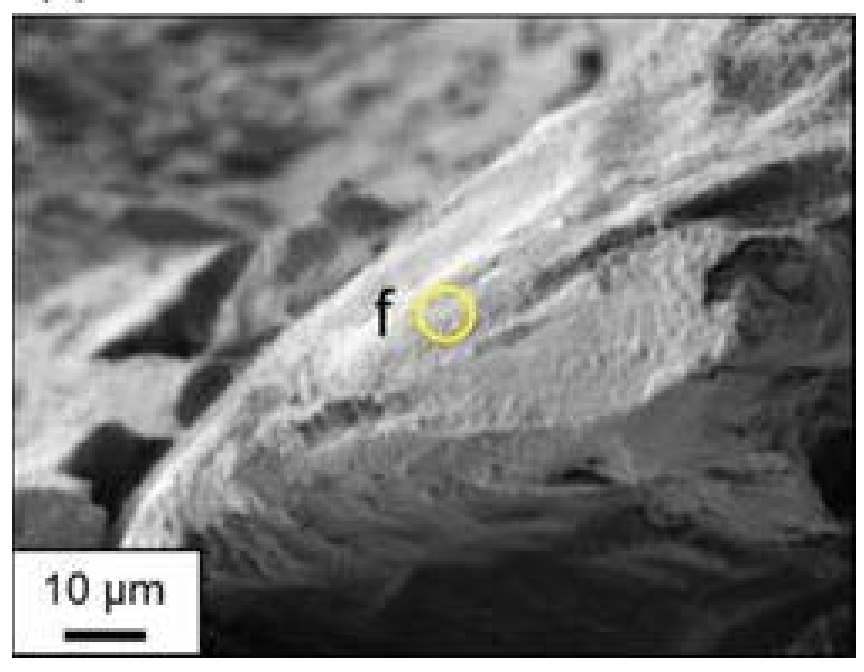

(c)

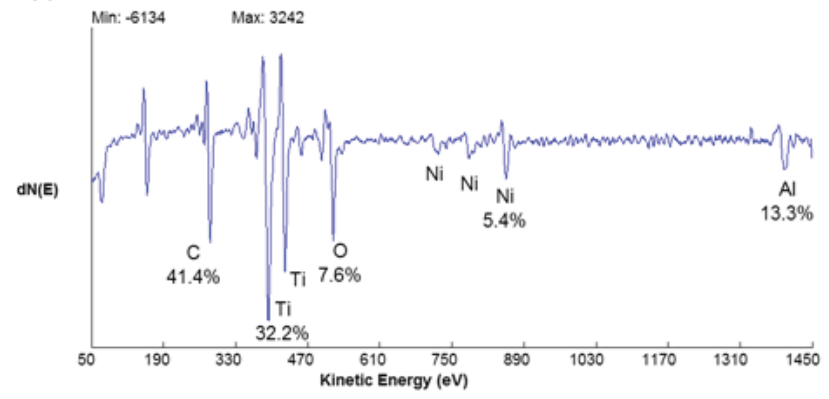

(d)

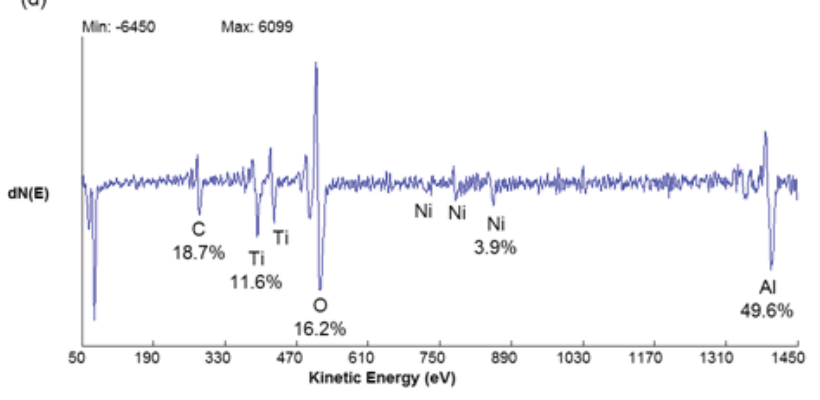

(e)

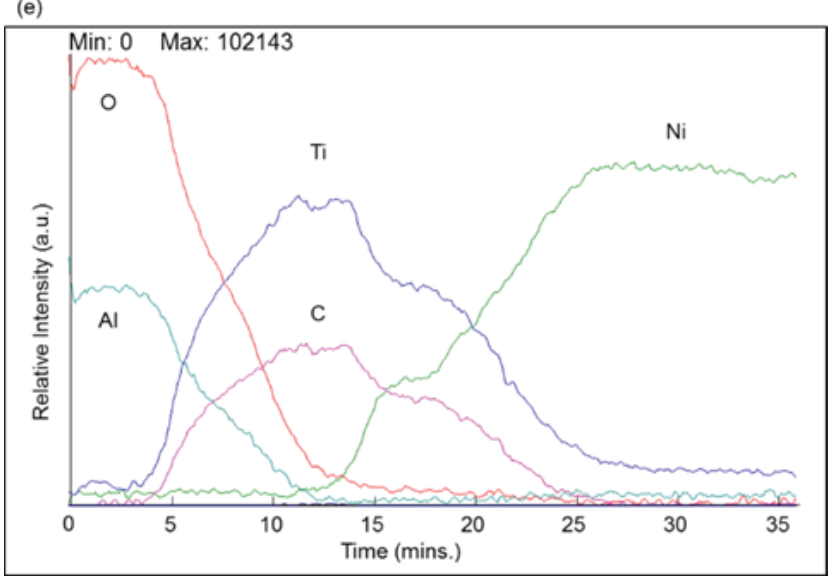

(f)

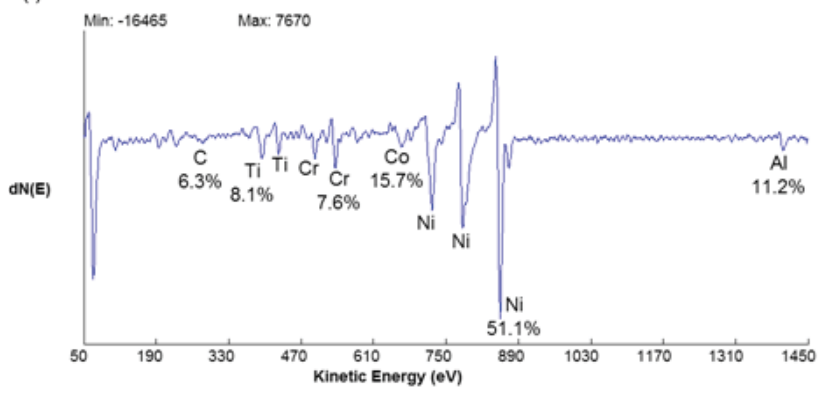

Figure 6 - Fractured Auger pin from top fill air cast blade. (a) NMI exhibiting discontinuous oxide structure; (b) Analysis location after depth profiling; (c) Corresponding AES spectrum taken from carbide region; (d) Corresponding AES spectrum taken from oxide region; (e) Depth profile of spot indicated in (a), sputter condition used produced a milling rate of $52 \mathrm{~nm} / \mathrm{min}$ on $\mathrm{Ta}_{2} \mathrm{O}_{5}$ standard; (f) Post-sputter AES spectrum of location indicated in (b). 
AES spectra indicate that there are distinct oxide-rich and carbide-rich locations. Due to spatial resolution limitations there is some signal blending between these locations whereby oxide regions exhibit some carbide signal and carbide regions exhibit some oxide signal. However, considering the surface sensitivity of AES, these results do indicate that this structure is heterogeneous, and exhibits distinct oxide and carbide phases. If the alumina phase were to exist as a continuous film that also possesses thick and thin regions, even in the thin regions theoretically covering the carbide phase in a continuous film, much more pronounced $\mathrm{Al}$ and $\mathrm{O}$ signals would be anticipated. This would be true even if the "thin" regions were a monolayer film, since the sample depth at which Auger electrons are generated is a maximum of only approximately $10 \AA$.

Depth profiling of oxycarbide inclusions was performed to determine the phase layering of the inclusion structure. This form of surface sensitive depth profiling would also allow for detection of phases that may be in the morphology of a thin interfacial film, which could have been previously undetected. Additionally, the thickness of each phase can be estimated by this technique. A representative depth profile is shown in Figure 6. It can be seen that the inclusion structure exhibits 3 distinct phases, which are layered as follows: $\mathrm{Al}_{2} \mathrm{O}_{3} / \mathrm{M}(\mathrm{Ti}, \mathrm{Mo}) \mathrm{C}$ carbide / Ni-matrix. Precise measurement of thickness is not possible by this method of depth profiling, however sputter times for depth profiling this inclusion can be approximately compared to milling rates of a $\mathrm{Ta}_{2} \mathrm{O}_{5}$ standard of known thickness. The ion beam conditions used produced a milling rate of $52 \mathrm{~nm} / \mathrm{min}$ using a $\mathrm{Ta}_{2} \mathrm{O}_{5}$ standard. The alumina layer was removed in approximately 7 mins of sputter time, and the carbide layer was removed in approximately $12 \mathrm{mins}$ of sputter time. Given that the material removal rate for alumina is approximately $13.8 \%$ of the milling rate of $\mathrm{Ta}_{2} \mathrm{O}_{5}$ [19], this indicates that the alumina layer is approximately $1.9 \mu \mathrm{m}$ in thickness. The oxide phase can therefore be estimated to be approximately 100-2000x the reported thicknesses of bifilms [5, 10]. This indicates that the oxide phase observed in oxycarbide inclusions is not evidence of a bifilm, and did not form by the proposed bifilm mechanism $[1,2,5]$. The results indicate that this oxide structure is likely from the formation of alumina dross inclusions, as these inclusions would be similar in morphology to those observed in this investigation [20].

In the case of no HIP samples, dendritic porosity was visible on the fracture surface of Auger pins. Some publications have claimed that bifilms are a primary source of casting porosity, and have stated that the surface of dendritic casting pores exhibit oxide films [1, 3-6, 8-10, 12-14, 21]. However, this assertion has not been conclusively confirmed, and SAM/AES fractography allowed for reliable investigation of dendritic porosity surface composition. In all of the Auger pins fractured and all of the dendritic pores analyzed in each pin, no pores exhibited AES spectra indicative of an oxide film, including air cast and turbulently filled specimens. Interestingly, there was a ubiquitous sulfur-rich layer identified on the surface of casting porosity. Every dendritic casting pore analyzed exhibited an AES spectrum with a distinct sulfur peak. An example of this is shown in Figure 3. The formation of this sulfur-enriched layer is likely due to bulk diffusion of $\mathrm{S}$, segregating to the free surface of the interior porosity. This agrees well with previous Auger analysis of nickel surfaces, which has shown that upon heating a nickel sample with sulfur content of $<10 \mathrm{ppm}$ in an Auger microprobe to $600-900^{\circ} \mathrm{C}$, a strongly sulfur-enriched surface layer develops in approximately 1-2 mins [22]. The major difference observed in the current investigation is that sulfur segregation was observed in internal free surfaces rather than an exterior free surface, and the formation of the sulfur enriched layer was due only to diffusion occurring during cool-down following casting. Further, the observation of prime importance is the absence of continuous oxide films, as would be anticipated if the observed dendritic casting pores had formed due to the presence of bifilms.

Oxy-carbide Characterizaton:

Oxycarbide inclusions were identified during metallographic analysis of some air cast IN100 (Figure 7).

(a)

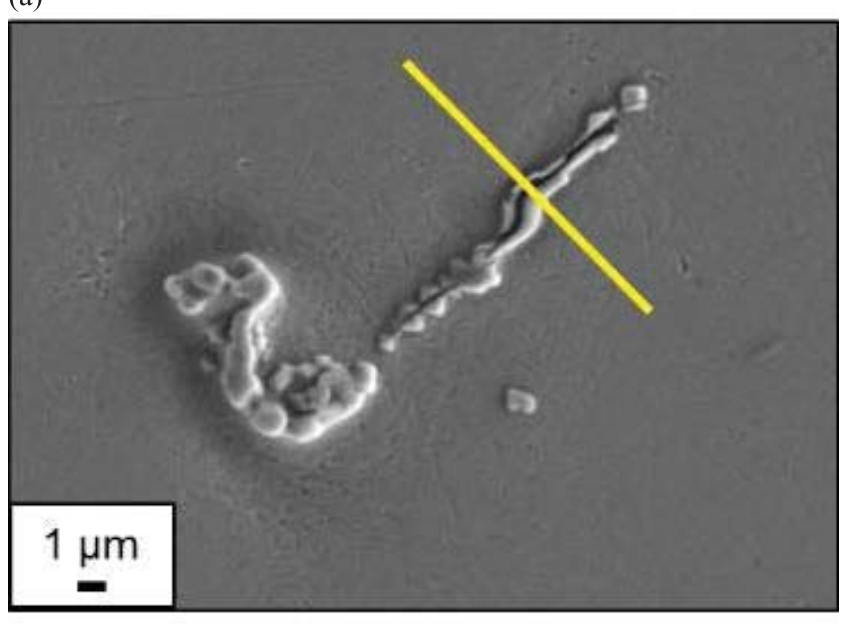

(b)
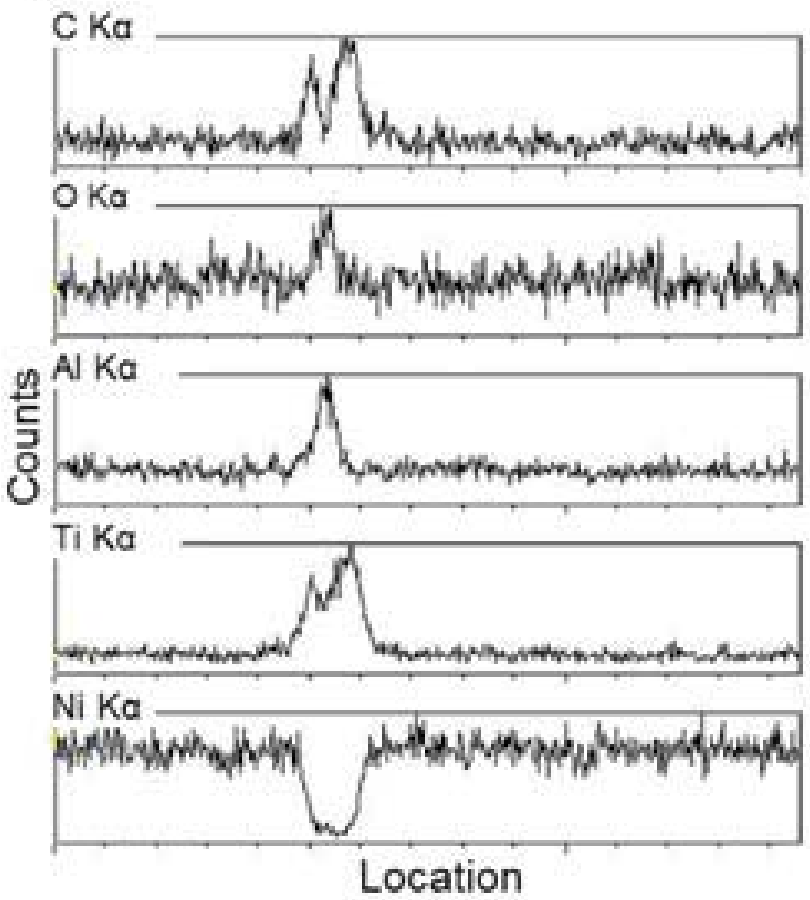

Figure 7. SEM metallography of layered structure in Ti oxycarbide inclusion in air cast, top filled, and as cast tensile sample. (a) Secondary electron image of location analyzed; (b) EDS line-scan of oxycarbide inclusion, line indicated in "a" 
Since no evidence of oxide films was observed in any sample, this type of inclusion was the only structure exhibiting an oxide phase. It was also noted that the morphology of Ti oxycarbide stringer inclusions was similar to inclusions that had been identified as thickened bifilms in other studies [5]. When observed metallographically, such inclusions frequently exhibited the appearance of being a tangled cluster. In the current limited bifilm literature, tangled clusters of inclusion stringers have been identified as thickened, or "old", bifilms [5].

Although the bifilm inclusion clusters are not necessarily identified as oxycarbide inclusions, the inclusion structures observed metallographically in this study do appear very similar in morphology. EDS line-scanning, as seen in Figure 7, identified the following layered structure across a region of the inclusion: $\mathrm{Ni}$ matrix/ $/ \mathrm{TiC} / \mathrm{Al}_{2} \mathrm{O}_{3} / \mathrm{TiC} / \mathrm{Ni}$-matrix.

An air-cast sample displaying microstructural NMIs was deep etched in order to elucidate the 3-dimensional structure of the oxycarbide inclusions. Deep etching revealed that the $\mathrm{Ti}$ oxycarbide stringer inclusions only appear stringy when metallographically polished, however the deep etched inclusions actually consisted of a cluster of very fine blocky $\mathrm{M}(\mathrm{Ti}, \mathrm{Mo}) \mathrm{C}$ carbides, as shown in Figure 8. Interestingly, the revealed inclusion structure only appeared to be $\mathrm{M}(\mathrm{Ti}, \mathrm{Mo}) \mathrm{C}$ carbide, whereas the previously metallographically polished surfaces (as demonstrated in Figure 8) showed the presence of alumina. This indicates that the alumina is only revealed after the inclusion exterior has been removed, suggesting that the oxycarbide inclusion actually consists of internal alumina that is enveloped 3-dimensionally by $\mathrm{M}(\mathrm{Ti}$, $\mathrm{Mo}) \mathrm{C}$ carbide. EDS analysis confirms the presence of alumina in the portion of the inclusion structure that has been polished. Unfortunately, given the limited spatial resolution of EDS analysis, and relative inaccuracy when quantifying low atomic number elements, quantitative EDS data is relatively inaccurate in this case. However, EDS spectra do clearly show an enrichment of $\mathrm{Al}$ and $\mathrm{O}$ in the polished region (Figures $8 \mathrm{f}$ and $8 \mathrm{~g}$ ) of the inclusion in Figure $8 \mathrm{~d}$.

This structure is worth noting, as bifilms are theorized to be a nucleation site for MC carbides. In this case, an alumina inclusion does appear to be acting as a nucleant for MC carbides. The presence of abundant and very fine MC carbides suggests that these carbides nucleated more rapidly than is typical in a cast structure. Their presence on the surface of the internal alumina also suggests that these carbides have nucleated heterogeneously. Although this agrees with some prevailing theories on bifilms [1, $5,15]$, this does not indicate that the internal alumina is a bifilm, since similar behavior would be anticipated from any alumina inclusion.

MC carbide nucleation on alumina inclusions in superalloy systems has been documented in other studies [23-25], as well as MC carbide nucleation on alumina inclusions in IN100 $[26,27]$. In these studies typical morphologies of MC carbides (blocky, $\sim 20 \mu \mathrm{m}$ ) have been observed containing alumina "cores" that vary in shape from film-like to spherical. The prevailing theory among these reports is that small oxide and nitride particles in the melt behave as heterogeneous nucleation sites for the precipitation of $\mathrm{MC}$ carbides. As the melt cools, $\mathrm{MC}$ carbides begin to nucleate just below the liquidus temperature of the alloy. Following nucleation, the carbide grows and envelops the alumina core. This is mechanistically similar to the bifilm-assisted carbide nucleation theories that have been proposed, however it is important to make the distinction that the nucleating inclusion does not need to be a bifilm. Mechanistically, any alumina inclusion would be capable of triggering this behavior. It is possible that the inclusions observed in this study have formed in a manner similar to the alumina-corecontaining carbide structures discussed. Given the morphology of the fine blocky external $\mathrm{TiC}$, it is proposed that this structure is caused by rapid and abundant heterogeneous $\mathrm{MC}$ carbide nucleation on the surface of an alumina dross inclusion.

To characterize the structure of the internal alumina in the Ti oxycarbide inclusions, and determine if the internal alumina could be a bifilm, an oxycarbide inclusion observed in an air cast sample prepared for metallography was removed via focused ion beam (FIB) lift-out. It should also be noted that exposure to HIP and heat treatment cycles did not appear to have a significant effect on the appearance of the NMIs. Since the oxycarbide inclusions did not appear to be affected by HIP and heat treatment cycles, it is likely that the NMIs were invariant to exposure to elevated temperatures. This indicates that if there were a bifilm present, it likely has not undergone bulk oxide thickening as would be expected based on the bifilm model.

A scanning transmission electron microscopy (STEM) image of the sample removed by FIB lift-out can be seen in Figure 9a, showing a profile view of the Ti oxycarbide inclusion. An EDS line-scan of the sample yields results that are in agreement with Auger depth profiling, indicating that the layered structure (in this case viewed in profile, orthogonal to the plane of previous metallographic imaging) is Ni-matrix, an outer layer of $\mathrm{TiC}$, and internal alumina. The sum spectrum shown indicates the presence of magnesium. The presence of $\mathrm{Mg}$ in an inclusion is often indicative that there had been a mold/metal interaction, with the molten superalloy stripping (deoxidizing) $\mathrm{Mg}$ content from the melt crucible to result in trace $\mathrm{Mg}$ content [28].

A bright field TEM (BF-TEM) image of the sample removed by FIB lift-out can be seen in Figure 10a, showing several internal boundaries which are shown by high resolution TEM (HRTEM) to be grain boundaries in Figures 10b through 10e. These results indicate that the Ti oxycarbide inclusion is comprised of fine polycrystalline external $\mathrm{M}(\mathrm{Ti}, \mathrm{Mo}) \mathrm{C}$ carbide and ultrafine polycrystalline internal alumina. It should be noted that there is no indication of pre-existing cracks due to bifilms at these interfaces, and the analyzed interfaces appear to be bound. Much of the ultrafine grained internal alumina appears to be multiple grains in width. However, some locations of this sample clearly contain a single grain spanning the width of the internal alumina structure. This indicates that the internal alumina was not formed from a bilayer of alumina films that have been sintered together and does not exist as an unbound preexisting crack. It is proposed that the alumina core observed is a polycrystalline alumina inclusion, with the morphology of a single oxide layer that is dense and bound, as opposed to an unbound bilayer. Considering that this type of inclusion was only observed in air cast alloys, it is also clear that the alumina core is a dross inclusion. 
(a)

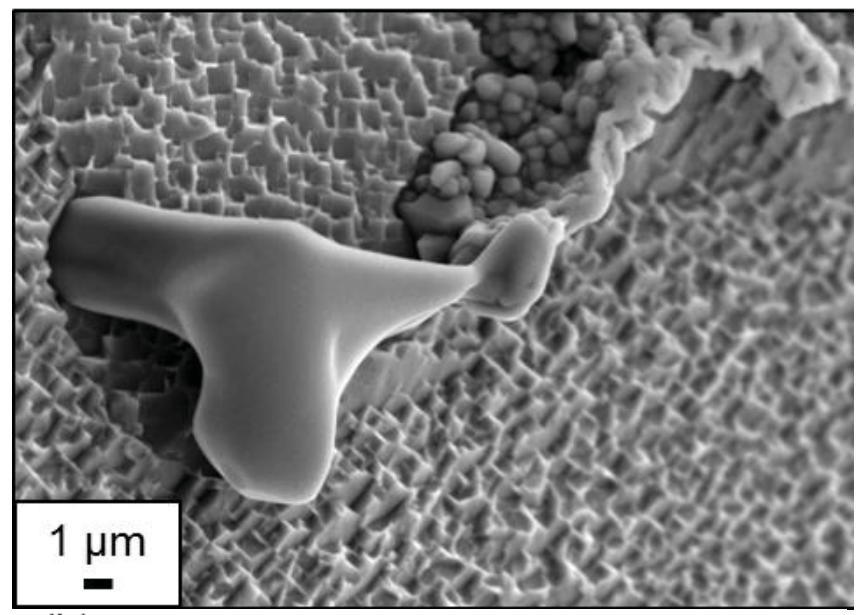

(b)

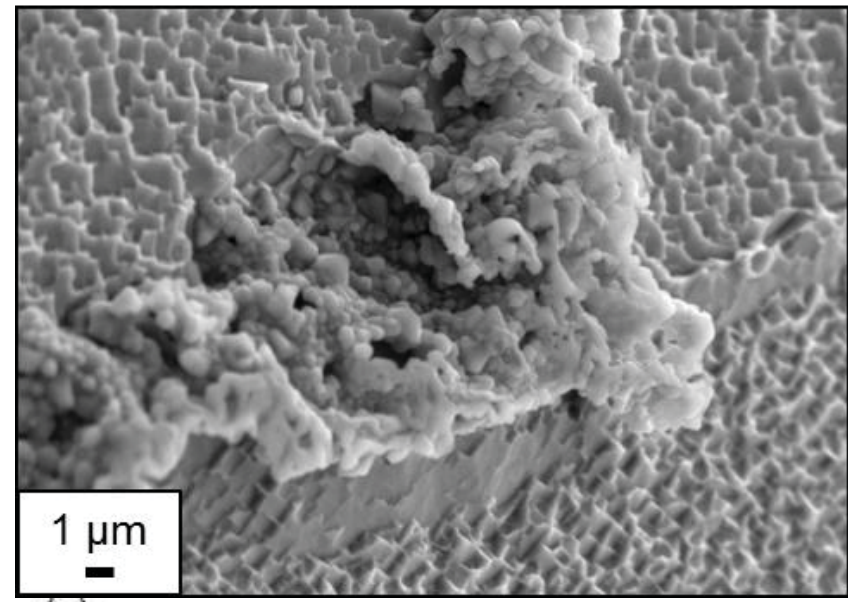

(c)

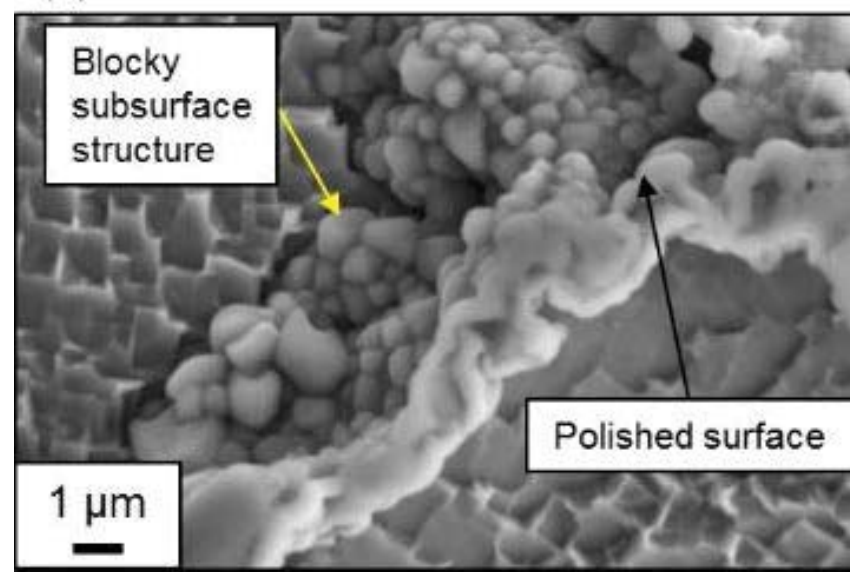

(d)

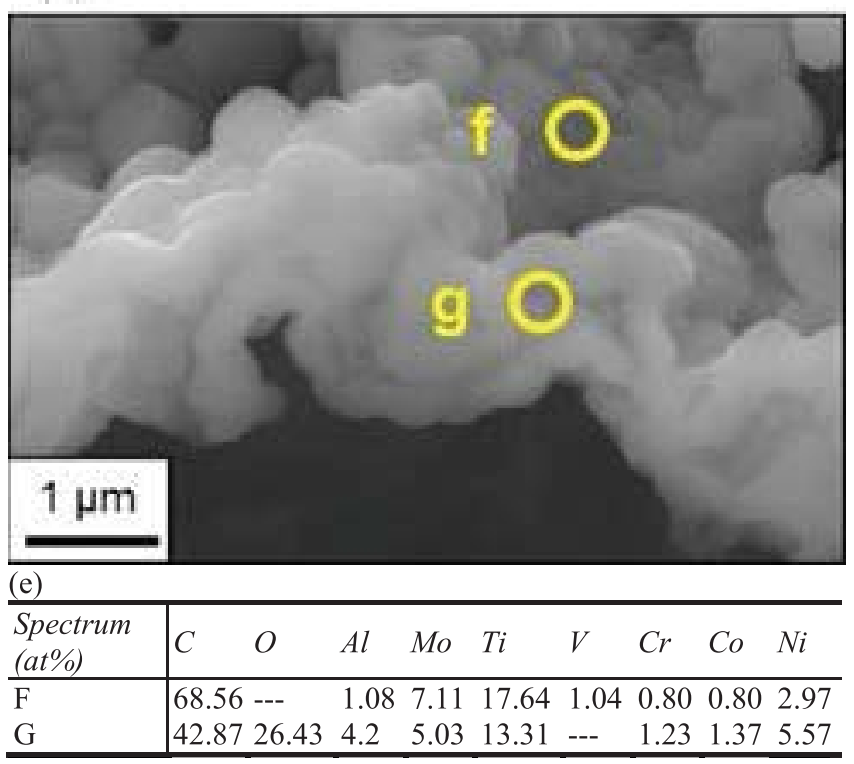

(f)

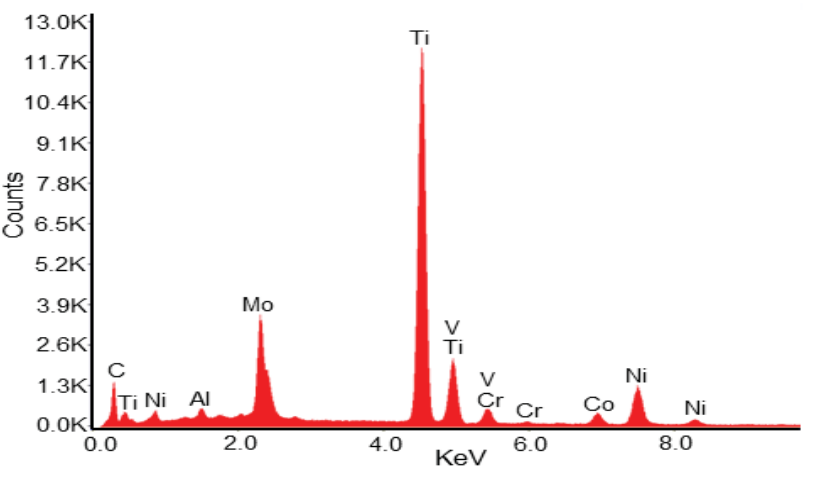

(g)

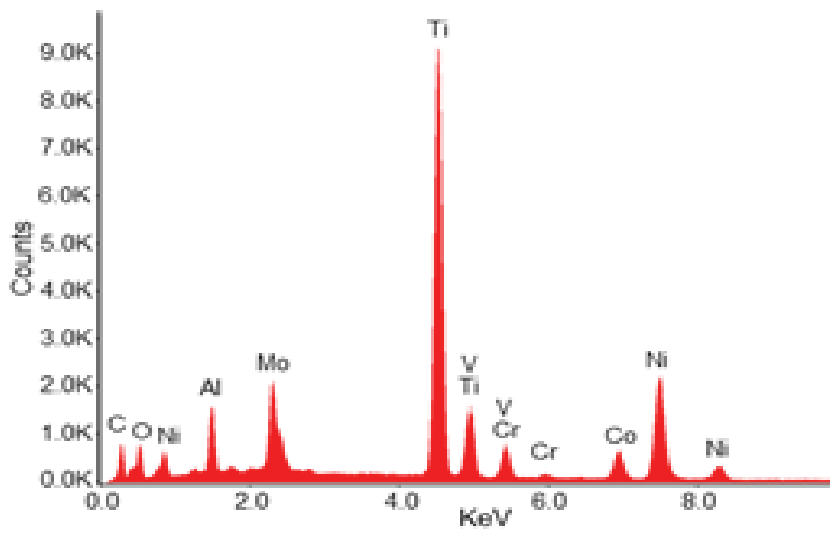

Figure 8. Analysis of deep-etched oxycarbide inclusion. (a \& b) Secondary electron imaging of deep-etched inclusion; (c) Secondary electron imaging of deep-etched inclusion showing the previously metallographically polished surface and revealed subsurface structures; (d) Secondary electron imaging of site chosen for EDS analysis; (e) Quantitative EDS of spots indicated in "d"; (f) EDS spectrum from spot indicated in "d"; (g) EDS spectrum from spot indicated in "d" 
(a)

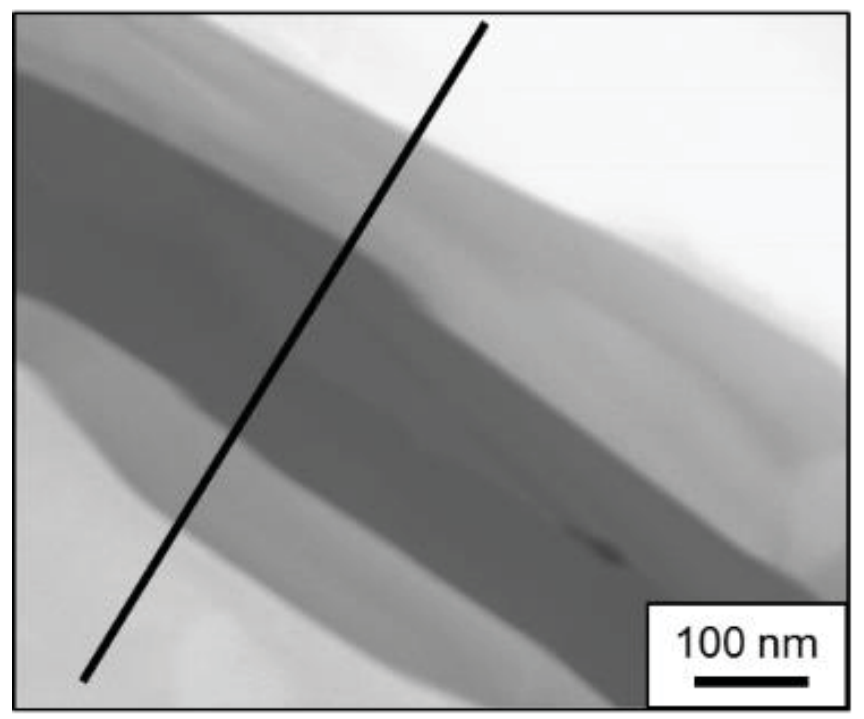

(b)

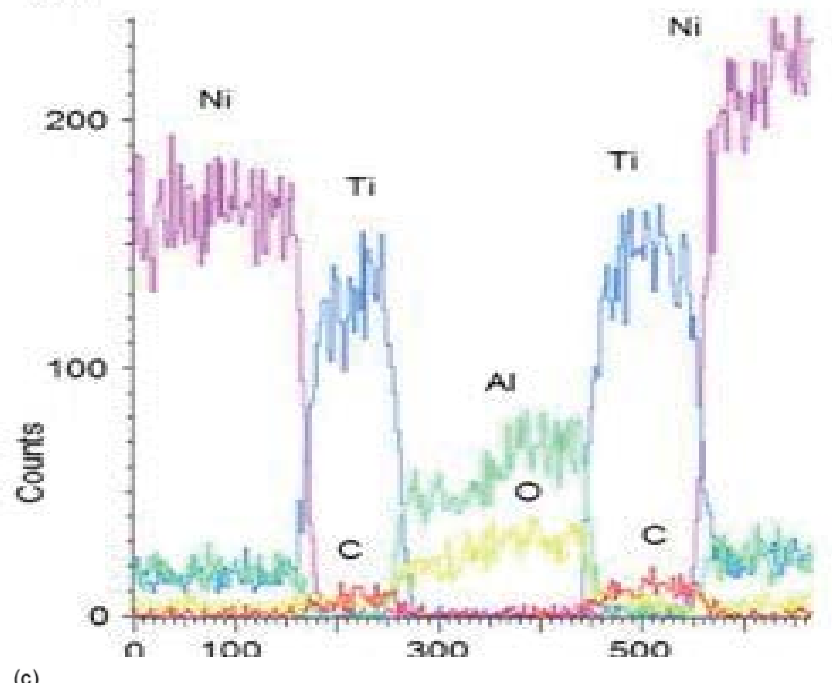

(c)

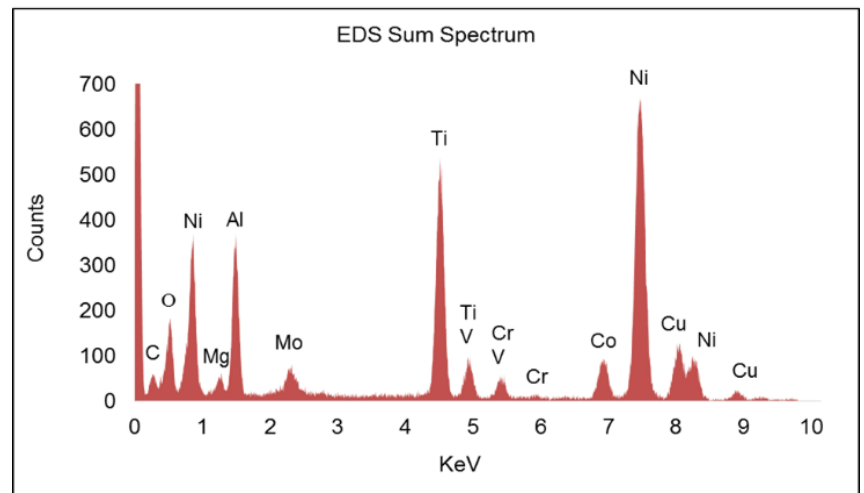

Figure 9. Analysis of layered oxycarbide inclusion. (a) STEM image showing inclusion structure and line-scan location; (b) EDS line-scan indicating the layering in the inclusion structure and location of each phase; (c) EDS sum spectrum generated from linescan location indicated in "a"

\section{Summary}

No evidence of bifilms was observed in any of the samples examined in this study. Cleavage planes, fractured carbides, dendritic porosity, and oxycarbide inclusion stringers that were observed on fracture surface were not necessarily evidence of the presence of bifilms in IN100. No evidence of oxide bifilms were observed in any of the fractographic or microstructural features examined in this study. The findings of this study conflict strongly with previous reports pertaining to bifilms. An array of mechanical behaviors that would be expected to be strongly influenced by the presence of bifilms did not exhibit an observable change in properties. Several previous reports have identified casting and processing parameters in Al-based systems that reportedly yielded a noticeable effect on bifilm formation and resultant mechanical properties $[3,5,6,9,10,12,15,20,21,23,25,26]$.

Other investigations have stated that bifilms are observable in Ni-based superalloy systems [1, 3, 18]. This study investigated fundamental underpinnings of bifilm theories, namely the effects of casting turbulence and HIPing on mechanical behavior, and was not able to identify an influence due to bifilms on Ni-based superalloy IN100. The lack of trends observed between turbulently and non-turbulently cast IN100, and similarly for HIP and non-HIP, is striking. This indicates that either bifilms were present in all the material analyzed, but not positively identified during characterization, or that bifilms were not an active mechanism in the mechanical behaviors investigated for IN100.

The results observed in this study pertain to one casting process and alloy system. However, IN100 was selected for this study because it was the material utilized in the component identified by Campbell and Tiryankioglu [1] as the cause of the fatal aircraft crash. Due to the discrepancy between observed results in this study and anticipated results from thorough review of bifilm literature, further investigation is necessary. The results of this study indicate that oxide bifilms were not a prevalent mechanism of room temperature tensile or fatigue fracture in IN100. Compelling and conclusive evidence would need to be presented in order to indicate otherwise. It is also suggested that reexamination of current bifilm theories may be necessary.

\section{Acknowledgements}

The authors would like to thank our collaborators at the Alcoa Howmet Research Center, Whitehall, MI, and the University of Florida Major Analytical and Instrumentation Center 


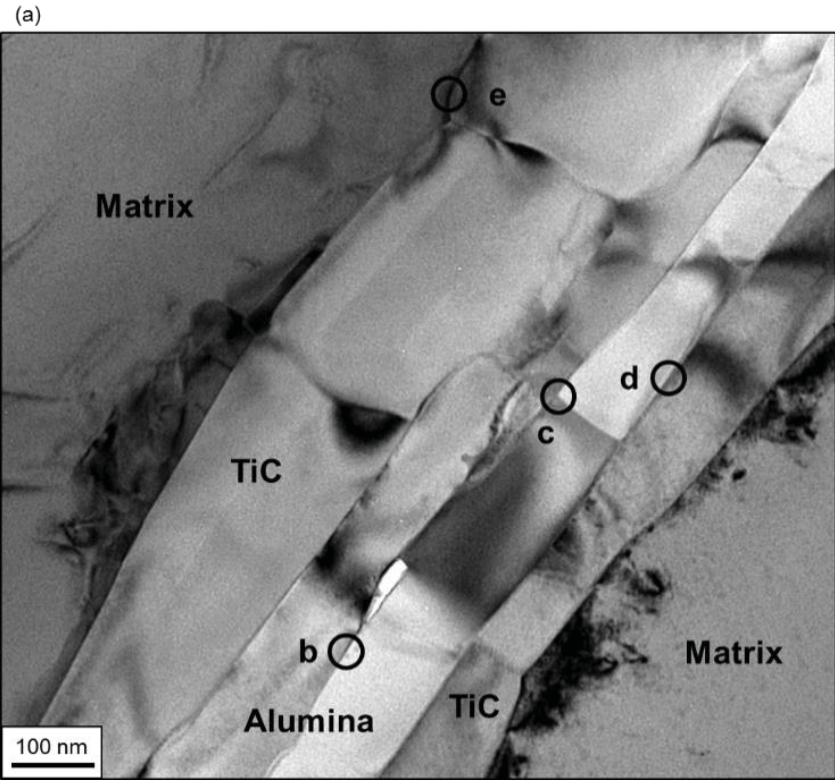

(b)

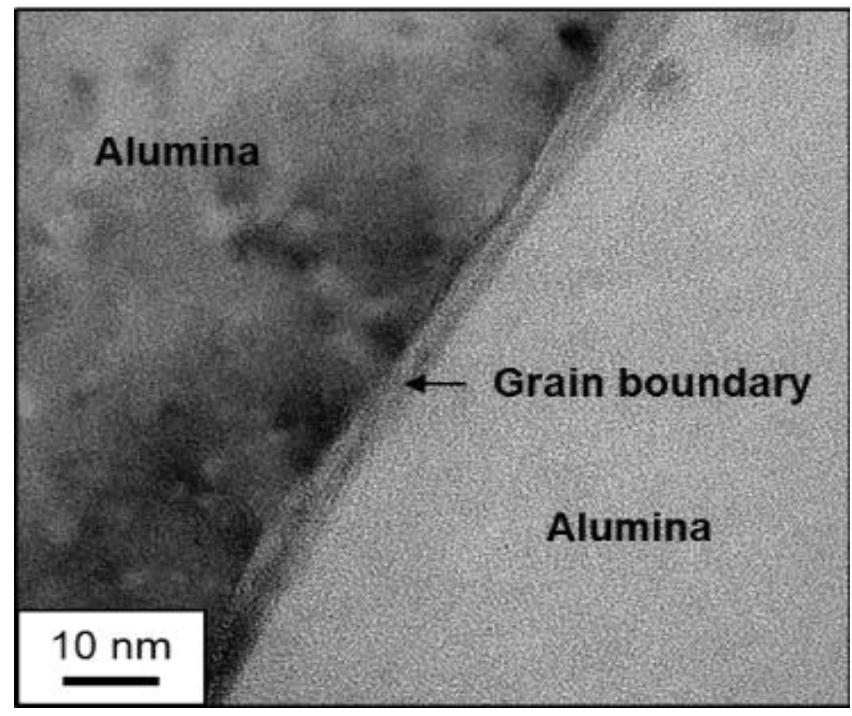

Figure 10. TEM analysis of internal interfaces in oxycarbide inclusion. (a) Bright-field imaging of inclusion; (b-e) HR-TEM imaging of grain boundary locations indicated in "a" (c)

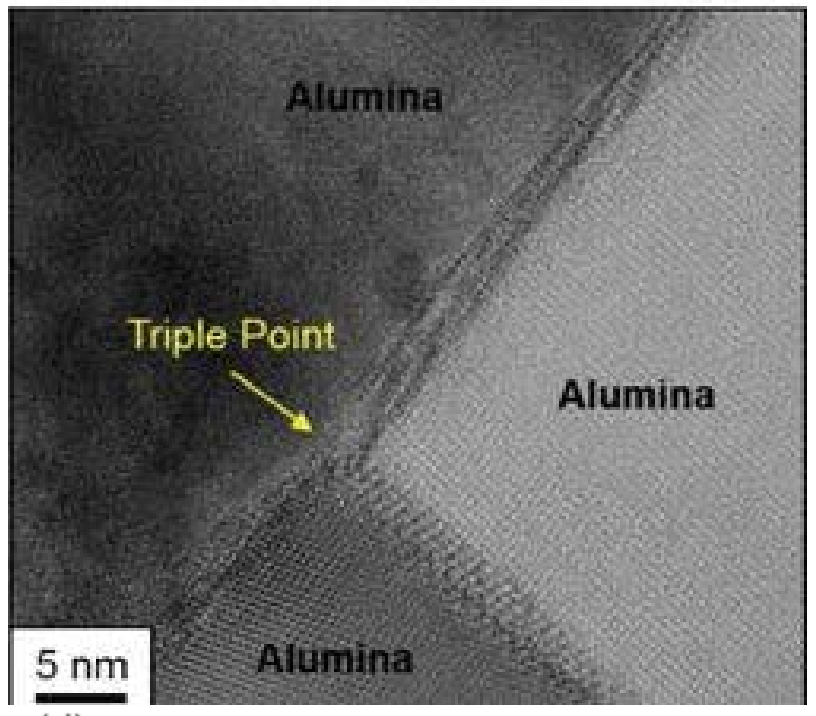

(d)

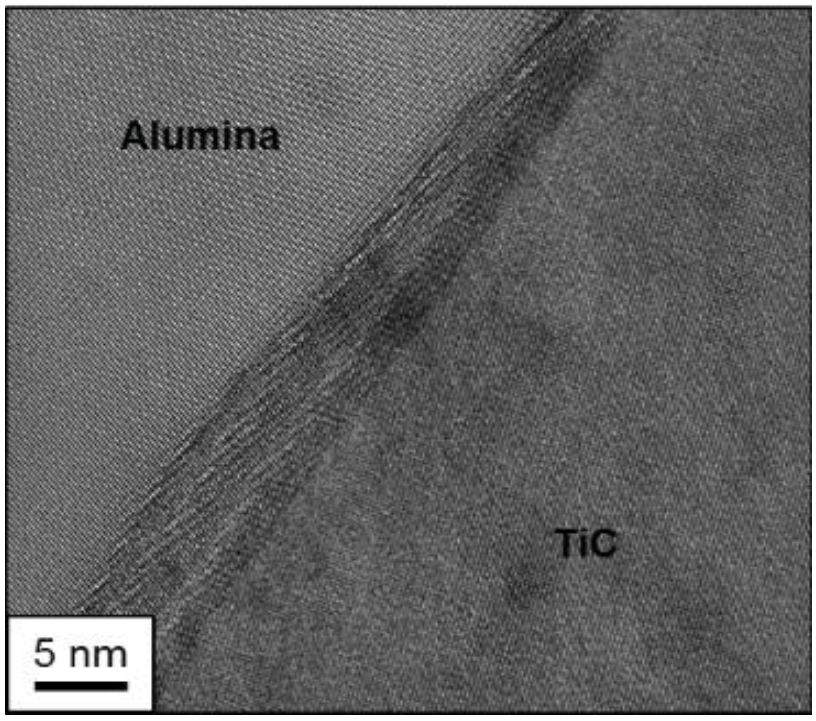

(e)

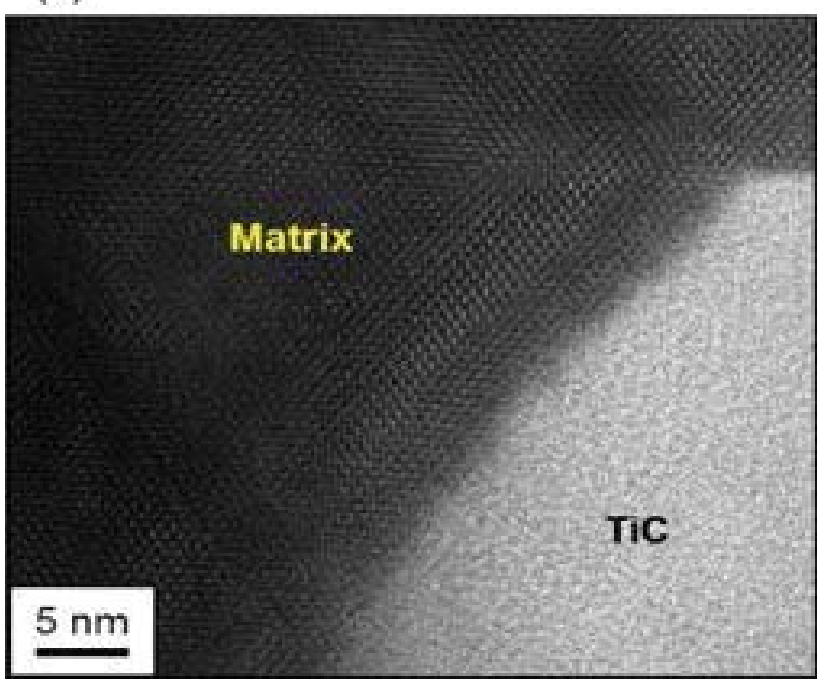




\section{References}

[1] J. Campbell and M. Tiryakioglu, "Bifilm Defects in Ni-Based Alloy Castings, Metall. Trans. B, 43 (2012), 902-914.

[2] A. Rashid and J. Campbell, "Oxide Defects in a Vacuum Investment-cast Ni-based Turbine Blade", Metall. Trans. A, 35A (2004), 2063-2071.

[3] J. Campbell, "Entrainment Defects", Mater. Sci. Tech., 22 (2006), 127-145.

[4] J. Campbell: Castings: The New Metallurgy of Cast Metals, (Burlington,MA: Butterworth-Heinemann, 2003), 17-69.

[5] J. Campbell, "Stop Pouring, Start Casting", Int. J. Metalcast., 6, (2012), 7-18.

[6] D. Dispinar and J. Campbell, "Porosity, hydrogen and bifilm content in Al alloy castings", Mater. Sci. Eng. A, 528A, (2011), 3860-3865.

[7] D. Dispinar, S. Akhtar, A. Nordmark, M. DiSabatino, and L. Arnberg, "Degassing, hydrogen and porosity phenomena in A356", Mater. Sci. Eng. A, 527A, (2010), 3719-3725.

[8] D. Li, J. Campbell, and Y. Li, "Filling system for investment cast Ni-base turbine blades", J. Mater. Process. Tech., 148, (2004), 310-316.

[9] J. Staley, M. Tiryakioglu, and J. Campbell, "The effect of hot isostatic pressing (HIP) on the fatigue life of A206-T71 aluminum castings, Mater. Sci. Eng. A, 465, (2007), 136-145.

[10] J. Staley, M Tiryakioglu, and J. Campbell, "The Effect of Increased HIP Temperatures on Bifilm and Tensile Properties of A206-T71 Aluminum Castings", Mater. Sci. Eng. A, 460, (2007), 324-334.

[11] M. Tiryakioglu, J. Staley, and J. Campbell, "The effect of structural integrity on the tensile deformation characteristics of A206-T71 alloy castings", Mater. Sci. Eng. A, 487, (2008), 383387.

[12] X. Dai, X. Yang, J. Campbell, and J. Wood, "Effects of Runner System Design on the Mechanical Strength of Al-7Si-Mg Alloy Castings", Mater. Sci. Eng. A, 354, (2003), 315-325.

[13] G. Eisaabadi, P. Davami, S. Kim, and N. Varahram, "Effects of Hydrogen and Oxides on Tensile Properties of Al-Si-Mg Cast Alloys", Mater. Sci. Eng. A, 552, (2012), 36-47.

[14] M. Tiryakioglu, J. Campbell, and J. Staley, "The influence of structural integrity on the tensile deformation of cast $\mathrm{Al}-7 \mathrm{wt} \% \mathrm{Si}$ 0.6wt\%Mg alloys", Scripta Mater., 49, (2003), 873-878.

[15] C. Nyahumwa, N. Green, and J. Campbell, "Effect of mould filling on fatigue properties of cast aluminum alloys", Metall. Trans. A, 32, (2001), 358-365.

[16] B. Eisaabadi, P. Davami, S. Kim, and M. Tiryakioglu, "The Effect of Melt Quality and Filtering on the Weibull Distributions of Tensile Properties in Al-7\% Si-Mg Alloy Castings", Mater. Sci. Eng. A, 579, (2013), 64-70.
[17] T. Denda, P. Bretz, and J. Tien, "Inclusion size effect on the fatigue crack propagation mechanism and fracture mechanics of a superalloy", Metall. Trans. A, 23A, (1992), 519-526.

[18] R. Miner, "Fatigue", Superalloys II: High-Temperature Materials for Aerospace and Industrial Power, pp. 263-289, C. Sims, N. Stoloff, and W. Hagel eds., Wiley, New York, NY, 1984.

[19] M. Gell, G. Leverant, and C. Wells, "Fatigue Strength of Nickel-Base Superarlloys", Proc. Achievement of High Fatigue Resistance in Metals and Alloys, pp. 113-153, ASTM, Philadelphia, PA, 1970.

[20] A. Rashid and J. Campbell, "Oxide defects in a vacuum investment-cast Ni-base turbine blade", Metall. Trans. A, 35A, (2004), 2063-2071.

[21] J. Campbell, "Entrainment", Castings: The New Metallurgy of Cast Metals, (Burlington, MA: Butterworth Heinemann, 2003), 17-69.

[22] L. Harris, "Some observations of surface segregation by Auger electron emission", J. Appl. Phys., 39, (1968), 1428-1431.

[23] J. Chen, J. Lee, C. Jo, S. Choe, and Y. Lee, "MC Carbide Formation in Directionally Solidified Mar-M247LC Superalloy": Mater. Sci. Eng. A, 247, (1998), 113-125.

[24] P. Quested and M. McLean, "Solidification Morphologies in Directionally Solidified Superalloys", Mater. Sci. Eng., 65, (1984), 171-180.

[25] S. Cockcroft, A. Mitchell, D. Tripp, A. Schmalz, and T. Degawa, "Inclusion Precipitation in Superalloys", Proc. Superalloys 1992, Eds., S. Antolovich, R. Stusrud, R. MacKay, D. Anton, T. Khan, R. Kissinger, and D. Klarstrom. (Warrendale, PA: TMS, 1992), 577-586.

[26] R. Fernandez, J. Lecomte, and T. Kattamis, "Effect of Solidification Parameters on the Growth Geometry of MC Carbides in IN100 Dendritic Monocrystals", Metall. Trans. A, 9A, (1978), 1381-1386.

[27] F. Beneduce, A. Mitchell, S. Cockcroft, and A. Schmalz, Primary Carbide Solution During the Melting of Superalloys", Proc. Superalloys 1996, Eds., R. Kissinger, D. Deye, D. Anton, A. Cetel, M. Nathal, T. Pollock, and D. Woodford, (Warrendale, PA: TMS, 1996), 465-469.

[28] G. Bouse and J. Mihalisin, "Metallurgy of Investment Cast Superalloy Components", Superalloys, Supercomposites, and Superceramics, Eds., J. Tien and T. Caulfield., (Boston, MA: Academic Press, 1989), 99-147. 